\title{
Sulfur dioxide in the tropical marine boundary layer: dry deposition and heterogeneous oxidation observed during the Pacific Atmospheric Sulfur Experiment
}

\author{
Ian Faloona • Stephen A. Conley • Byron Blomquist • Antony D. Clarke • \\ Vladimir Kapustin • Steven Howell • Don H. Lenschow • Alan R. Bandy
}

Received: 22 September 2009 / Accepted: 25 February 2010 /

Published online: 24 March 2010

(C) The Author(s) 2010. This article is published with open access at Springerlink.com

\begin{abstract}
Research flights with the National Center for Atmospheric Research (NCAR) C130 airborne laboratory were conducted over the equatorial ocean during the Pacific Atmospheric Sulfur Experiment (PASE). The focused, repetitive flight plans provided a unique opportunity to explore the principal pathways of sulfur processing in remote marine environments in close detail. Fast airborne measurements of $\mathrm{SO}_{2}$ using the Drexel University APIMS (Atmospheric Pressure Ionization Mass Spectrometer) instrument further provided unprecedented insight into the complete budget of this important sulfur gas. In general, turbulent mixing in the marine boundary layer (MBL) continuously depletes $\mathrm{SO}_{2}$ due to the shallow convection of the tropical trade wind regime by venting the gas into the buffer layer (BuL) above. However, on nearly one-third of the flights a net import of $\mathrm{SO}_{2}$ into the MBL from the $\mathrm{BuL}$ was observed. Concurrent measurements of the DMS budget allowed for a heterogeneous S(IV) oxidation rate to be inferred from the $\mathrm{SO}_{2}$ budget residual. The average heterogeneous loss rate was found to be $0.05 \mathrm{~h}^{-1}$, which taken in conjunction with the observed aerosol surface area distributions and $\mathrm{O}_{3}$ levels indicates that the supermicron aerosols maintain a near neutral $\mathrm{pH}$. The average dry deposition velocity of $\mathrm{SO}_{2}$ was found to be $0.4 \mathrm{~cm} \mathrm{~s}^{-1}$, about $30 \%$ lower than predicted by standard parameterizations. The yield of $\mathrm{SO}_{2}$ from DMS oxidation was found to be near unity. The mission averages indicate that approximately $57 \%$ of the $\mathrm{SO}_{2}$ in the MBL is lost to aerosols, $27 \%$ is subject to dry deposition, $7 \%$ is mixed into the BuL, and $10 \%$ is oxidized by $\mathrm{OH}$.
\end{abstract}

\section{Faloona $(\bowtie) \cdot$ S. A. Conley}

Department of Land, Air, \& Water Resources, University of California, Davis, CA 95616-5270, USA

e-mail: icfaloona@ucdavis.edu

B. Blomquist $\cdot$ A. D. Clarke $\cdot$ V. Kapustin $\cdot$ S. Howell

School of Ocean and Earth Science and Technology, University of Hawaii, Manoa, Honolulu, HI 96822 , USA

D. H. Lenschow

National Center for Atmospheric Research, Boulder, CO, USA

A. R. Bandy

Chemistry Department, Drexel University, Philadelphia, PA 19104-2875, USA 
Keywords Sulfur cycle $\cdot$ Marine boundary layer $\cdot$ Sea salt aerosols $\cdot$ S(IV) oxidation · Dry deposition

\section{Introduction}

If the principal criterion for judging the utility of a scientific hypothesis were quantity and vigor of the research that it instigates, then the "CLAW" hypothesis (Charlson et al. 1987) has certainly been one of the most successful in the recent decades of earth science. At the heart of the "CLAW" hypothesis is the idea that dimethylsulfide (DMS), produced by ocean surface ecosystem processes, can have a profound impact on the populations of cloud condensation nuclei (CCN) over the world's oceans, and thus may act as a strong lever on the planetary albedo via cloud microphysics thereby possibly regulating climate in a homeostatic manner. The details of just the atmospheric processing branch of this circuit have spurred considerable debate about, for example, the role of sea salt aerosols and marine organic compounds in cloud nucleation (O'Dowd et al. 1999; Leck and Bigg 2005; Clarke et al. 2006), the chemical yield of $\mathrm{SO}_{2}$ from DMS oxidation, and the loss of $\mathrm{SO}_{2}$ to the ocean surface or uptake onto supermicron marine aerosols.

Regardless of its exact role in climate regulation, since the discovery that DMS is the primary natural source of atmospheric sulfur (Lovelock et al. 1972; Maroulis and Bandy 1977; Andreae and Raemdonck 1983) great effort has been made to understand the chemical processing of this compound so ubiquitous in marine air. Yet even a clear correlation with the primary oxidation product, $\mathrm{SO}_{2}$, has been observed only intermittently. The early studies of Bandy et al. (1992), Huebert et al. (1993), and Yvon et al. (1996) in the marine boundary layer (MBL) found minimal relationship between the two species on diurnal time scales, leading to considerable confusion about the source of $\mathrm{SO}_{2}$ and non-sea salt (NSS) sulfate in remote maritime regions. Seasonal and day-to-day variations observed at Amsterdam Island in the Southern Indian Ocean did exhibit some positive correlations (Putaud et al. 1992) confirming the suspicion that $\mathrm{SO}_{2}$, with an expected lifetime of only a couple of days, should be linked to DMS far from anthropogenic, or volcanic, sources. But it was not until a field campaign deployed on Christmas Island in the Equatorial Pacific that a clear diurnal pattern was observed in both species, $180^{\circ}$ out of phase (Bandy et al. 1996). Since then others have confirmed similar relationships (De Bruyn et al. 1998, 2002; Shon et al. 2001) but the $\mathrm{SO}_{2}$ yield remains uncertain. A recent survey of 20 modeling and experimental studies by Faloona (2009) illustrates the scientific ambiguity of this single product yield, which ranges from 0.3 to 0.98 .

The Achilles heel of all investigations of the $\mathrm{DMS}-\mathrm{SO}_{2}$ relationship to date has been the inability to measure all the important processes in the system simultaneously: most notably, the flux of DMS out of the ocean, turbulent exchange between the MBL and above, and the dry deposition of $\mathrm{SO}_{2}$ into the ocean separate from heterogeneous oxidation rates. The Pacific Atmospheric Sulfur Experiment (PASE) was planned to address these issues by bringing to bear the latest analytical instrumentation installed onboard the NCAR C-130 research aircraft to probe the relatively homogeneous MBL of the equatorial Pacific. The Atmospheric Pressure Ionization Mass Spectrometers (APIMS) developed by Drexel University are field proven to be fast and sensitive enough to measure turbulent fluxes of $\mathrm{SO}_{2}$ (Thornton et al. 2002) and DMS (Bandy et al. 2002; Faloona et al. 2005) by eddy covariance. With careful attention paid to the scalar budgets of both compounds during each flight, it was possible to account for all the dynamical terms (horizontal advection, vertical mixing, surface fluxes) and solve for the chemical terms. 


\section{Methods}

\subsection{Instrumentation}

\subsubsection{Atmospheric pressure chemical ionization mass spectrometry}

APIMS measurements of DMS and $\mathrm{SO}_{2}$ utilize soft chemical ionization at atmospheric pressures with hydronium ions (in positive mode) and $\mathrm{CO}_{3}{ }^{-}$and its hydrates (in negative mode), respectively. Ultimately, the detected ions are $\mathrm{DMSH}^{+}(\mathrm{m} / \mathrm{e}=63)$ and $\mathrm{SO}_{5}{ }^{-}(\mathrm{m} / \mathrm{e}=$ 112). The air sample for each instrument is drawn by a Venturi pump through a Nafion ${ }^{\circledR}$ dryer and across a ${ }^{63} \mathrm{Ni}$ radioactive source. In the $\mathrm{SO}_{2}$ APIMS a small amount of ozone is added to ensure quantitative formation of the reagent ion, $\mathrm{CO}_{3}{ }^{-}$, from ambient $\mathrm{CO}_{2}$. Subsequent reaction yields $\mathrm{SO}_{5}{ }^{-}$(Eisele and Berresheim 1992; Möhler and Arnold 1992) which is then detected in a differentially pumped quadrupole mass spectrometer. The permeation dryer is required to maintain a nearly constant low humidity, keeping the formation of ion-hydrates in check. Each instrument's sensitivity is continuously monitored by isotopic dilution $\left({ }^{34} \mathrm{SO}_{2}\right.$ and tri-deuterated DMS) delivering a true measure of mixing ratio that is sampled at $25 \mathrm{~Hz}$. This measurement technique obviates the need for the Webb correction (Webb et al. 1980), and eliminates any spurious contribution from water vapor flux due to subtle fluctuations in air density caused by drying the sample stream with a permeable membrane (DeLacy and Bandy 2008). Instrumental details of the specific APIMS techniques are described in Bandy et al. (2002) and Blomquist et al. (2009) for DMS, and Thornton et al. (2002) for $\mathrm{SO}_{2}$.

Most instrumental analysis involves the removal of a background of some kind, and the APIMS is no exception. The DMS zero is established by passing the sample stream through $150 \mathrm{~cm}^{3}$ of gold-coated $3 \mathrm{~mm}$ Pyrex beads (Blomquist et al. 2009). The removal of $\mathrm{SO}_{2}$ is considerably easier as it is simply passed through $7.6 \mathrm{~m}$ of $6.4 \mathrm{~mm}$ o.d. $\mathrm{Cu}$ tubing. The count rate averaged over each zeroing interval, usually 1-2 min each flight leg, for each analyte is subsequently removed from the rest of the measurement period. Typical background counts measured during PASE were similar in magnitude to the $\mathrm{SO}_{2}$ signal $\left(50\right.$ pptv $\sim 5,000$ counts $\left.\mathrm{s}^{-1}\right)$.

\subsubsection{Aerosol surface area spectrum}

In order to cover the entire size range from 0.01 to $10 \mu \mathrm{m}$, aerosol size spectra resulted from merging the size distributions from four different instruments. The fine aerosols, with particle diameters, $D_{p}$, between 0.01 and $0.20 \mu \mathrm{m}$ were measured with a custom-made Radial Differential Mobility Analyzer (RDMA). Larger particles $\left(0.1<D_{p}<10.0 \mu \mathrm{m}\right)$ were sampled with a modified 'Long' DMA (LDMA, TSI Inc., $0.10<D_{p}<0.50 \mu \mathrm{m}$ ), a Laser Optical Particle Counter (OPC, PMS Inc., $0.12<D_{p}<8.0 \mu \mathrm{m}$ ) and a TSI model 3321 Aerodynamic Particle Sizer (APS, $0.78<D_{p}<10.0 \mu \mathrm{m}$ ). The APS size distributions were converted from aerodynamic to geometric diameters to provide a consistent merger. All instruments were operated inside the aircraft near ambient pressure, but at cabin temperatures. The size distributions were measured after mixing with desiccated air to achieve dryer conditions with sample relative humidities (RH) in the range of $10-40 \%$. The changes of particle sizes as RH varies from 10 to $40 \%$ are small compared to our other size distribution measurement uncertainties, and are therefore neglected. Drying minimizes water uptake by the aerosol so that the distributions preferentially reflect the aerosol components over the water component (Howell et al. 2006). During horizontal legs the 
RDMA and OPC operated with a thermal pre-conditioning unit that cycled the aerosol through $40^{\circ} \mathrm{C}, 150^{\circ} \mathrm{C}$ and $350^{\circ} \mathrm{C}$ to drive off the volatile and semi-volatile aerosol constituents, allowing inference of size-resolved aerosol chemistry (Clarke et al. 2004).

In order to correct the in-situ total aerosol surface area to the ambient RH outside the aircraft, we use a simplified algorithm of aerosol hygroscopic growth described in Kapustin et al. (2006) and Howell et al. (2006). First the aerosol size distributions are divided into accumulation and coarse modes by finding the minima in volume distributions between 0.4 and $1.0 \mu \mathrm{m}$. The accumulation mode is then split into volatile and refractory fractions by using the accumulation mode volume lost after heating to $350^{\circ} \mathrm{C}$. The coarse mode is assumed to be pure sea-salt during PASE. The fine and accumulation modes were assumed to be a typical internal mixture of a small percentage of non-volatile components (estimated at $50 \%$ sea-salt with some non-volatile organic carbon, soot, etc.) and a dominant volatile component (estimated at $25 \%$ organic carbon and $75 \%$ sulfate salts). Hygroscopic growth of each mode was calculated based on the following assumptions: no RH growth for dustlike components, sea salt growth following Tang et al. (1997), and the volatile component growth according to Kapustin et al. (2006).

\subsection{Theory of reactive scalar budgets in a turbulent fluid}

Chemical mass-balance equations are better known in micrometeorology as scalar budgets and are founded upon the principles of mass and momentum conservation, and fluid incompressibility. Thus any scalar, like a chemical mixing ratio or potential temperature, in a turbulent fluid flow is customarily decomposed into a Reynolds mean and a stochastic, fluctuating component as is done for the overall velocity (vector) field. A generic scalar, $c$, has a governing conservation equation representing the balance of its in-situ chemical sources, $P$, first-order chemical losses, $L$, and inexorable molecular diffusion characterized by a diffusion coefficient, $D_{c}$ (i.e., Fick's second law):

$$
\frac{d c}{d t}=P-L c-D_{c} \nabla^{2} c
$$

Then considering the medium is a turbulent fluid, $c$ is written as the sum of its mean and fluctuating components, $c=C+c^{\prime}$, the material derivative on the lhs of (1) is broken out into an Eulerian time derivative and advection terms, and the resultant equation is Reynolds averaged to derive a budget equation for the mean:

$$
\frac{\partial C}{\partial t}=-\frac{\partial}{\partial z}\left\langle w^{\prime} c^{\prime}\right\rangle-U \frac{\partial C}{\partial x}+P-\left(L_{\text {homo }}+L_{\text {hetero }}\right) C
$$

Where the brackets indicate Reynolds averaging and the $x$-dimension has been aligned with the mean horizontal wind, $U$. Because of the large Péclet number $\left(=U \Lambda / D_{c}\right.$, where $\Lambda$ is an outer dimension of the flow), the molecular diffusion term in (1) is considered as negligibly small relative to turbulent mixing within the volume of the MBL. Furthermore, it was determined from the flight data that the horizontal turbulent flux divergence terms were negligible relative to the vertical (first term on rhs) and subsequently ignored. In this airborne work we treat the mean scalar budget for the entire turbulent boundary layer and focus the analysis only on this layer, the MBL. By direct eddy covariance measurements of the fluxes at various altitudes, and horizontal monitoring of the mesoscale gradients, the first and second terms on the rhs of (2) are tightly constrained in the flight region. Analysis of the DMS budget during PASE using this methodology is fully described by Conley et al. (2009). 


\subsection{Chemistry of $\mathrm{SO}_{2}$ in the $\mathrm{MBL}$}

We use the results of Conley et al. (2009) to provide an estimate of the in-situ $\mathrm{SO}_{2}$ production from DMS oxidation, which depends on the uncertain yield parameter $\gamma$ mentioned previously:

$$
P_{\mathrm{SO}_{2}}=\gamma\left(k_{\mathrm{OH}+D M S}[\mathrm{OH}][D M S]\right)
$$

Rigorously $\gamma$ is a bulk product yield of all DMS oxidation channels; however Conley et al. (2009) found that the budget of DMS was consistent with oxidation solely by the $\mathrm{OH}$ radical. The reaction rate coefficient is the sum of a $\mathrm{H}$-abstraction and an $\mathrm{OH}$ addition pathway, but at the mean temperature of the MBL (297 K) during PASE, the former is three times faster (Atkinson et al. 2004) than the latter. Although chamber experiments show the net $\mathrm{SO}_{2}$ yields to be in the range of 0.7-0.8 at room temperature (Barnes et al. 2006 and references therein), their applicability here is dubious because of the presence of $\mathrm{NO}_{\mathrm{x}}$ at levels well above those typical of remote marine environments. At least one study of the $\mathrm{NO}_{\mathrm{x}}$ dependence does indicate an increase of $\mathrm{SO}_{2}$ yield at lower $\mathrm{NO}_{\mathrm{x}}$ levels (Patroescu et al. 1999). The review by Faloona (2009) reports a mean value from field and modeling estimates of this yield to be $0.7 \pm 0.2$.

The in-situ chemical losses of $\mathrm{SO}_{2}$ are believed to be gas phase reaction with $\mathrm{OH}$ and uptake followed by oxidation in aerosols and cloud droplets. The homogeneous loss is simply:

$$
L_{\text {homo }}=k_{\mathrm{OH}+\mathrm{SO}_{2}}[\mathrm{OH}]
$$

Assuming a mean daytime $\mathrm{OH}$ concentration of $5 \times 10^{6}$ molecules $/ \mathrm{cm}^{3}$, which is consistent with the DMS budget (Conley et al. 2009) estimates and the concomitant aircraft observations (Mauldin, personal communication), and using the recommended rate of Atkinson et al. (2004), $\mathrm{k}_{\mathrm{OH}+\mathrm{SO} 2}=8 \times 10^{-13} \mathrm{~cm}^{3}$ molecule ${ }^{-1} \mathrm{~s}^{-1}$, the first-order loss to homogeneous oxidation is $0.015 \mathrm{~h}^{-1}$ during the daylit hours. The overall first-order heterogeneous oxidation rate is considered here to be the result of mass transfer to the particles, $k_{m t}$, in series with the oxidation by dissolved $\mathrm{O}_{3}$ and $\mathrm{H}_{2} \mathrm{O}_{2}$ proceeding simultaneously as presented in the works of Suhre et al. (1995), Mari et al. (1999), and Song et al. (2003):

$$
\frac{1}{L_{\text {hetero }}}=\frac{1}{k_{m t}}+\frac{1}{k_{O_{3}}+k_{\mathrm{H}_{2} \mathrm{O}_{2}}}
$$

The aqueous oxidation rates of dissolved $\mathrm{SO}_{2}$ by $\mathrm{O}_{3}$ and $\mathrm{H}_{2} \mathrm{O}_{2}$ are evaluated in terms of the aerosol liquid water content, the Henry's Law coefficients, equilibrium constants for $\mathrm{SO}_{2}$ partitioning into $\mathrm{S}(\mathrm{IV})$ species, aqueous reaction rates, and aerosol $\mathrm{pH}$ as formulated by Koch et al. (1999) and Mari et al. (1999). The $\mathrm{O}_{3}$ oxidation rate is particularly sensitive to $\mathrm{pH}$, which is notoriously difficult to measure in the atmosphere (Keene and Savoie 1998; Faloona 2009). According to Faloona (2009) the overall heterogeneous reaction by these oxidants varies over three orders of magnitude for an aerosol $\mathrm{pH}$ change from 5.5 to 7 . This extreme sensitivity is exploited here by solving for the $\mathrm{SO}_{2}$ chemical loss from the budget equation (Eq. 2) and finding the required matching pH. The mass-transfer rate is integrated across the observed aerosol size spectrum using the method presented by Schwartz (1986) as laid out in Faloona (2009). Some models of gas to particle mass transfer use the empirical formulations of Fuchs and Sutugin (1970), however, Sander (1999) showed that the difference from the Schwartz (1986) formulation is merely a few percent averaged over an entire size spectrum. 


\subsection{Measurement of $\mathrm{SO}_{2}$ fluxes}

To date direct measurements of $\mathrm{SO}_{2}$ fluxes by eddy covariance have been attempted only infrequently and are restricted to cases of very large concentrations over vegetated surfaces (Matt et al. 1987; Padro et al. 1993; Meyers et al. 1998). These measurements, upon which all extant dry deposition parameterizations are based (Wesely and Hicks 2000), were made using a relatively fast flame photometric detection instrument responsive to most sulfur gases. Aside from their lack of selectivity these instruments tended to be plagued by very high noise levels and a water dependent sensitivity, and it is unclear to what extent these limitations influenced the model parameterizations. Advancements made in the APIMS technique during the last decade have at last made possible the measurement of $\mathrm{SO}_{2}$ fluxes by aircraft (Thornton et al. 2002) even at low ambient levels without an interference from water vapor fluxes.

The covariance of the vertical wind with the $\mathrm{SO}_{2}$ signal was calculated over $200 \mathrm{~s}$ intervals after removing the mean and linear trend. Most constant altitude legs flown during PASE were $30 \mathrm{~min}$ in duration, permitting 9 independent flux measurements. The flight planning for PASE was originally based on Lagrangian circle patterns that drift with the mean wind such as had been implemented during the PEM-Tropics A (Davis et al. 1999) and DYCOMS-II (Stevens et al. 2003) campaigns. However, the high-rate $\mathrm{SO}_{2}$ observations made it immediately clear that even at different altitudes aircraft exhaust was rapidly mixed vertically throughout the MBL compromising our ability to perform a careful $\mathrm{S}$ budget in a fixed airmass. In response to this complexity, an alternate chevron pattern was developed. Transition turns between legs were made into the wind such that each leg tracked just slightly upwind of its immediate predecessor. In this way $30 \mathrm{~min}$ legs were flown consisting of two $\sim 90 \mathrm{~km}$ arms subtending $60^{\circ}$ approximately bisected by the mean wind direction.

The bandwidth from 0.005 to $25 \mathrm{~Hz}$ was determined after scrutinizing all the full leg cospectra and comparing the covariances calculated over different intervals to ensure the inclusion of all relevant scales in the flux estimates. This was done for most of the observed high-rate scalars including potential temperature, water vapor, DMS (Conley et al. 2009), and $\mathrm{SO}_{2}$. Decreasing the bandwidth systematically reduced the flux magnitudes, and increasing it only introduced more scatter due to mesoscale "noise" that appeared to be random. The $200 \mathrm{~s}$ averaging width represents $22 \mathrm{~km}$ of straight flight track, which is larger than expected a priori. The necessity of such a long filter suggests that organized convection plays a significant role in conducting scalar fluxes in these tropical boundary layers. The presence of roll structures in the study region was identified by cloud streets with 5-15 km spacing noticeable on most visible satellite images of the region during the entire campaign (Fig. 2). Roll structures in the MBL typically align $\sim 10^{\circ}$ with respect to the mean wind (Atkinson and Zhang 1996) and the aircraft trajectories would intersect them only at $10-45 \mathrm{~km}$ intervals.

One concern in making eddy covariance measurements is the possibility of an ambient trace gas, such as the often vexing water vapor, affecting the instrumental sensitivity or background. If the influence is large enough then ambient fluctuations in the interfering compound, due to its own turbulent flux, can be superposed on that of the target analyte. In order to investigate this potential problem, the $\mathrm{SO}_{2}$ instrument was operated in blanking mode for an entire flight leg during RF06. The background signal was processed in an identical manner as the $\mathrm{SO}_{2}$ signal during normal legs and the $\mathrm{SO}_{2}$-equivalent flux was determined to be $-0.012 \mathrm{ppt} \mathrm{ms}^{-1}$. This covariance is $<10 \%$ the magnitude of the average $\mathrm{SO}_{2}$ flux observed near the surface and top of the MBL, and smaller than most standard 
deviations of the mean for the 8 or $9200 \mathrm{~s}$ segments within any given 30 min flux leg. Furthermore, a compilation of all the shorter zeroing intervals (usually 1-2 min) from

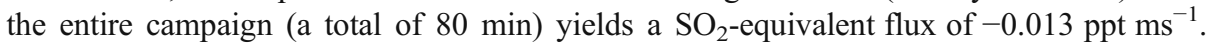
The short 'blank fluxes' exhibit no relationship with altitude nor with their neighboring $\mathrm{SO}_{2}$ and latent heat fluxes, and we thus consider the background signal fluctuations to be random and uncorrelated with the wind, and to not systematically influence the flux measurements.

The instrumental lag time with respect to the vertical wind measurement, obtained from sensors in the radome of the $\mathrm{C}-130$, is assessed from the phase angle spectrum and/or lag correlation plots for each leg (Conley et al. 2009). The $\mathrm{SO}_{2}$ signal showed a consistent correlation maximum at a $3 \mathrm{~s}$ lag, which is comparable to the expected flow delay of the sample stream into the APIMS. Scrutiny of the lag correlation plots revealed a secondary correlation peak with vertical wind at approximately $0.5 \mathrm{~s}$. This correlation was also evident in the background signal observed during the blank leg described above, wherein the flow was delayed through the $25^{\prime} \mathrm{Cu}$ tube scrubber (an additional $\sim 10 \mathrm{~s}$ residence time). The background signal thus appears to respond to inertial impulses of the aircraft and not to an interfering ambient gas, and while the correlation with wind is significant it is shifted in time such that its contribution to the $\mathrm{SO}_{2}$ flux measurement is random with mean zero. Figure 1 shows the average normalized cospectral shapes of the $\mathrm{SO}_{2}$, binned into three altitude categories $\left(z<0.15 \mathrm{z}_{\mathrm{i}}, 0.15 \mathrm{z}_{\mathrm{i}}<\mathrm{z}<0.75 \mathrm{z}_{\mathrm{i}}, 0.75 \mathrm{z}_{\mathrm{i}}<\mathrm{z}<\mathrm{z}_{\mathrm{i}}\right)$. The figure illustrates the general situation for $\mathrm{SO}_{2}$ in this environment: dry deposition at the ocean surface, vertical mixing into the buffer layer aloft, and near zero fluxes at intermediate altitudes. Also shown is the cospectrum of the background signal with the vertical wind during the blank leg of

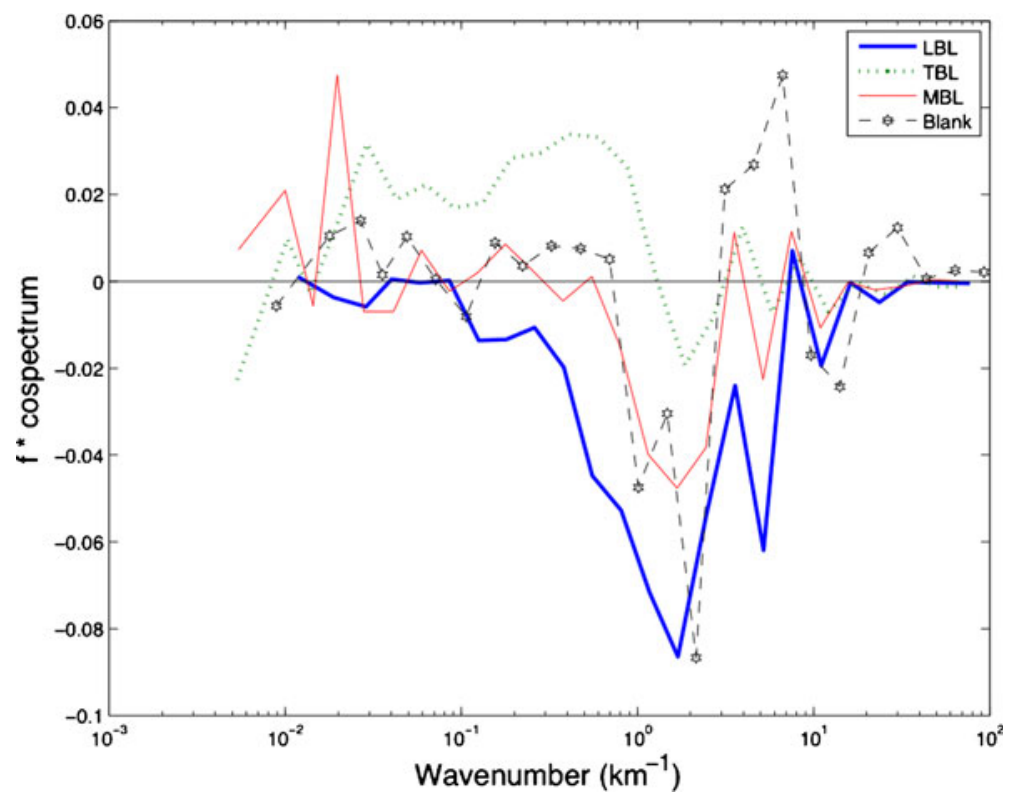

Fig. 1 Averaged cospectra of $\mathrm{SO}_{2}$ and vertical wind, $w$, binned into three altitudes for all 10 flights. The ordinate is scaled by frequency and thus has units of ppt $\mathrm{ms}^{-1}$. The abscissa is the frequency divided by true air speed (average $\sim 110 \mathrm{~ms}^{-1}$ ). LBL are all flight legs flown below $0.15 z_{i}$, MBL from $0.15 z_{i}$ to $0.75 z_{i}$, and TBL from $0.75 z_{i}$ to $z_{i}$ 
RF06 with a $3 \mathrm{~s}$ delay to mimic its influence on the calculated $\mathrm{SO}_{2}$ fluxes. It is apparent that while the fluctuations of the background signal do not correlate with vertical wind on average, the variability still influences the cospectral behavior of all the $\mathrm{SO}_{2}$ fluxes because of its apparent response to vertical accelerations of the aircraft (at $\sim 0.5 \mathrm{~s}$ ).

Because the cospectra exhibit atypical forms beyond $0.2 \mathrm{~Hz}\left(=1.8 \mathrm{~km}^{-1}\right.$ wavenumber $)$ another diagnostic check was made using cospectral similarity with water vapor. Assuming fidelity of the fast UV-hygrometer operated by NCAR's Research Aviation Facility, and assuming the cospectra of $w$ with water vapor and $\mathrm{SO}_{2}$ possess the same shape, then the flux of $\mathrm{SO}_{2}$ can be measured up to a certain frequency cutoff and the balance extrapolated by analogy with water vapor (Hicks and McMillen 1988). The mathematical scaling can be expressed as:

$$
\left\langle w^{\prime} \mathrm{So}_{2}{ }^{\prime}\right\rangle \cong \int_{0.005 \mathrm{~Hz}}^{25 \mathrm{~Hz}} \operatorname{Co}\left(w, s \mathrm{~s}_{2}\right) d f=\int_{0.005 \mathrm{~Hz}}^{0.2 \mathrm{~Hz}} \operatorname{Co}\left(w, s \mathrm{~s}_{2}\right) d f\left(\frac{\int_{0.005 \mathrm{~Hz}}^{25 \mathrm{~Hz}} \operatorname{Co}(w, q) d f}{\int_{0.005 \mathrm{~Hz}} \operatorname{Co}(w, q) d f}\right)
$$

where $\left\langle w^{\prime} \mathrm{SO}_{2}{ }^{\prime}\right\rangle$ is the eddy covariance of $\mathrm{SO}_{2}$ measured between 0.005 and $25 \mathrm{~Hz}, \mathrm{Co}(w, q)$ is the cospectrum of vertical wind, $w$, and specific humidity, $q$, and likewise with $\mathrm{SO}_{2}$. Notice that in the lower legs $\left(z<0.15 \mathrm{z}_{\mathrm{i}}\right)$ this cutoff is near the cospectral peak, but will overlay more and more of the total flux with increasing height above the surface. Using this methodology to estimate $\mathrm{SO}_{2}$ fluxes changed the mean surface deposition rate by less than $5 \%$. The remarkable correspondence between the eddy covariance $\mathrm{SO}_{2}$ fluxes and those estimated using cospectral similarity with water lead us to believe that the flux measurements, while subject to increased random errors due to the background fluctuations, were not systematically compromised during the experiment.

\section{$2.5 \mathrm{SO}_{2}$ deposition velocities}

Concurrent measurements of the governing parameters of surface similarity theorymomentum and buoyancy fluxes $\left(u_{*}^{2}\right.$ and $\left\langle w^{\prime} \theta_{v}{ }^{\prime}\right\rangle$, respectively) - and the preponderance of flight legs flown below $100 \mathrm{~m}$ provided an opportunity to probe the nature of $\mathrm{SO}_{2}$ deposition. The deposition velocity, $v_{d e p}$, is defined as the negative ratio between a trace gas's surface flux and its mean concentration at some reference height (usually $10 \mathrm{~m}$ )

$$
v_{d e p} \equiv \frac{-\left\langle w^{\prime} \text { So }_{2}{ }^{\prime}\right\rangle_{0}}{\left[S O_{2}\right]_{10 m}}
$$

Fairall et al. (2000) provide a very good overview of the basis for defining this relationship, showing that it can be developed from integrating the combined transport due to turbulence and molecular diffusion from the surface to the reference height. Using the flux-gradient relationships of surface layer similarity for both momentum and concentration (scalar), and assuming a null concentration at the interface yields an expression for deposition velocity

$$
v_{d e p}=\frac{k u^{*}}{\ln z_{10} / z_{0_{m}}+\ln _{z_{0_{m}} / z_{0_{s}}}+\psi_{s}}=\frac{1}{r_{a}+r_{b}}
$$

where $k$ is the von Karman constant $(\sim 0.38), z_{0 m}$ is the roughness length, $z_{0 s}$ is the scalar roughness length, and $\psi_{s}$ is the diabatic correction term (Benoit 1977). The deposition velocity can thus be construed as a sum of aerodynamic and surface resistances, $r_{a}$ and $r_{b}$, 
acting in series analogous to electrical circuits. The former is a consequence of turbulent transport below the reference height and the latter is related to molecular diffusion across the micro layer. Bypassing the specific issue of the exact value of $z_{0 m} / z_{0 s}$ can be accomplished by substituting the mean wind speed into the analogous wind shear similarity relationship so that

$$
r_{a}=\frac{U}{u_{*}^{2}}-\frac{\left(\psi_{m}-\psi_{s}\right)}{k u_{*}}
$$

with $\psi_{m}$ the diabatic correction for the wind profile. The surface resistance can be estimated using the relationship of Wesely and Hicks (1977)

$$
r_{b}=\frac{2}{k u_{*}^{*}}\left(\kappa / D_{s O_{2}}\right)^{2 / 3}
$$

where $\kappa$ is the thermal diffusivity of air and $D_{S o 2}$ is the diffusion coefficient of $\mathrm{SO}_{2}$ in air taken to be $1.3 \times 10^{-5} \mathrm{~m}^{2} \mathrm{~s}^{-1}$ (Massman 1998) for the conditions encountered in PASE. Only the air-side resistances are considered here because at a $\mathrm{pH}$ of 8.1 the effective Henry's Law coefficient of $\mathrm{SO}_{2}$ in seawater is $2 \times 10^{7} \mathrm{M} \mathrm{atm}^{-1}$, and therefore the uptake is gas-phase controlled (Schwartz 1992). The observed fluxes are corrected to a $10 \mathrm{~m}$ reference height based on the mean flux divergence term from each flight. The mean concentrations are corrected to $10 \mathrm{~m}$ based on the surface layer gradients expected from the similarity relationship, corrected for the stability using $\psi_{s}$. These combined corrections increased the resultant deposition velocities by an average of $15 \%$.

\subsection{Flight strategies}

Ten of the fourteen research flights conducted during PASE were suitable for a complete analysis of the $\mathrm{SO}_{2}$ budget in the marine boundary layer (Eq. 2). Figure 2 illustrates a typical flight strategy for one of these budget closure sorties (RF08). Vertical profiles beyond the trade wind inversion (typically near $1,500 \mathrm{~m}$ ) down to the surface (minimum


Fig. 2 Typical flight pattern from RF08. The left panel is altitude and the right is a plan view superimposed on a GOES-11 visible satellite image of the region taken near flight takeoff 
flight altitude of $30 \mathrm{~m}$ ) punctuate stacks of three level $30 \mathrm{~min}$ legs within the MBL and one in the buffer layer $(\mathrm{BuL})$. Aircraft turns required $\sim 100 \mathrm{~m}$ clearance above sea level so the lowest legs were split into two branches separated by a rise, turn, and descent pattern which was eliminated for the purpose of calculating fluxes. Figure 2 shows the chevron flight pattern that approximately stays fixed with respect to the Earth while the airmass advects through the study region carrying aircraft exhaust away. Because the scalar gradients along the line of the mean wind are the most important for advection (3rd term in Eq. 2), a long transect within the MBL was often flown at the end of the flight to survey the gradient more precisely and rapidly.

The first four terms in Eq. 2 are derived directly from the observations of $\mathrm{SO}_{2}$ and DMS (Conley et al. 2009). For each flight, all of the data collected below the MBL inversion base is fit using a multivariate regression to obtain the temporal change throughout the flight, as well as the gradients in all three dimensions. The advective term in Eq. 2 is estimated based on the dot product of the large-scale horizontal gradients observed by the aircraft and the mean wind in the study region (Conley et al. 2009). The second term in Eq. 2 is the vertical flux divergence, which results from (the difference between) dry deposition to the ocean surface and the combined action of convective pumping out and entrainment mixing into the MBL. Fluxes measured on each $30 \mathrm{~min}$ MBL leg are fit to a line establishing a slope representing the net effects of turbulent transport. Flights 5, 7, and 11 were specifically focused on the surface layer and each stack provided three legs below $\sim 200 \mathrm{~m}$ with an additional leg near the top of the MBL. Flights 6 and 13 were begun at night such that sunrise occurred near the middle of the second stack. The budgets for the night flights are calculated with only the data collected before dawn (from about 2:30 to 6:15 local time.)

\section{Results and discussion}

Table 1 summarizes the $\mathrm{SO}_{2}$ scalar budget for each of the ten flights of PASE under consideration. The first three columns, observed directly from the flights, correspond to the first three terms of Eq. 2: 'Trend'- $\partial\left[S_{2}\right] / \partial t$, 'Flux Div' $-\partial\left\langle w^{\prime} S_{2}{ }_{2}{ }^{\prime}\right\rangle / \partial z$, 'Advection' $-\vec{U}_{h} \cdot \nabla_{h}\left[S O_{2}\right]$, where the subscript $h$ represents the horizontal components

Table 1 Quantified terms of the $\mathrm{SO}_{2}$ budget

\begin{tabular}{|c|c|c|c|c|c|c|c|c|c|c|c|}
\hline Flight (RF) & $\begin{array}{l}\mathrm{SO}_{2} \text { Trend } \\
(\mathrm{ppt} / \mathrm{hr})\end{array}$ & $\begin{array}{l}\text { Flux Div. } \\
\text { (ppt/hr) }\end{array}$ & $\begin{array}{c}\text { Advection } \\
\text { (ppt/hr) }\end{array}$ & $\begin{array}{c}\text { DMS } \\
\text { decay } \\
\text { (ppt/hr) }\end{array}$ & $\begin{array}{l}\text { Net Loss } \\
\text { (ppt/hr) }\end{array}$ & $\begin{array}{c}\text { Aerosol } \\
\text { Loss }\left(h^{-1}\right)\end{array}$ & $\begin{array}{c}V_{\text {dep }} \\
(\mathrm{cm} / \mathrm{s})\end{array}$ & $\begin{array}{l}{\left[\mathrm{SO}_{2}\right]} \\
\text { (ppt) }\end{array}$ & $\begin{array}{l}\text { Net Error } \\
\text { (ppt/hr) }\end{array}$ & $\begin{array}{c}\begin{array}{c}\text { Surface } \\
\text { Area }\end{array} \\
\left(\mu \mathrm{m}^{2} / \mathrm{cm}^{3}\right)\end{array}$ & $\begin{array}{c}\text { Aerosol } \\
\text { pH }\end{array}$ \\
\hline 1 & 0.00 & -2.11 & 0.11 & N/A & N/A & & 0.21 & 63.8 & 0.32 & & \\
\hline 2 & 0.76 & -3.08 & 0.51 & 7.36 & -4.03 & -0.059 & 0.33 & 54.9 & 0.32 & 94.6 & 7.0 \\
\hline 3 & 4.50 & -1.92 & -0.45 & 7.43 & -0.56 & 0.004 & 0.33 & 55.2 & 0.37 & 98.1 & N/A \\
\hline 5 & 4.96 & -1.63 & -0.38 & 11.23 & -4.26 & -0.060 & 0.44 & 57.4 & 0.54 & 90.8 & 7.0 \\
\hline 8 & 2.77 & -0.73 & 1.81 & 5.88 & -4.19 & -0.088 & 0.32 & 40.7 & 0.36 & 58.8 & 7.2 \\
\hline 11 & 2.60 & -3.24 & 3.36 & 6.78 & -4.29 & -0.058 & 0.52 & 59.0 & 0.54 & 48.1 & 7.2 \\
\hline 12 & 3.41 & -2.19 & 0.73 & 7.39 & -2.51 & -0.042 & 0.40 & 43.9 & 0.52 & 87.3 & 7.0 \\
\hline 13 & -1.08 & -0.45 & 0.63 & 0.00 & -1.26 & -0.045 & 0.41 & 28.1 & 0.42 & 121.0 & 6.9 \\
\hline 14 & 5.85 & -1.76 & -2.06 & 11.29 & -1.62 & -0.009 & 0.39 & 68.1 & 0.50 & 91.9 & 6.7 \\
\hline
\end{tabular}


of the wind and scalar gradient. The net loss of DMS, assumed to be due to chemical oxidation, is from the work of Conley et al. (2009) and represents the in-situ production of $\mathrm{SO}_{2}$ scaled by an appropriate yield (3). The mission averaged horizontal gradient of $\mathrm{SO}_{2}$ was found to be aligned with that of DMS, directed to the north-northeast with a magnitude of approximately 7 pptv per degree. Because the prevailing trade wind flow was east-southeasterly, approximately perpendicular to the $\mathrm{SO}_{2}$ gradient, the advection term averaged close to zero for the entire mission; however, its contribution to the budget was found to be significant on any given flight and would have been a large source of error were it not measured. The shallow cumulus visible in Fig. 2 predominantly resided in the $\mathrm{BuL}$ above the MBL and therefore do not contribute to the budget of $\mathrm{SO}_{2}$ confined to the MBL.

\subsection{Aerosol $\mathrm{pH}$ and oxidation of $\mathrm{SO}_{2}$}

A complete closure of the budget in Eq. 2 is not possible because of ambiguity in some of the chemical parameters, namely the yield from DMS oxidation ( $\gamma$ in Eq. 3), and the heterogeneous oxidation of $\mathrm{SO}_{2}$ on aerosols (5) which strongly depends on $\mathrm{pH}$. However, the nighttime budgets are void of production and can therefore be solved explicitly for the heterogeneous loss rate required to close the budget. Results of this analysis indicates that first-order aerosol loss rates at night are 0.10 and $0.045 \mathrm{~h}^{-1}$. Table 2 is a survey of estimates of heterogeneous S(IV) oxidation rates compiled from the literature of the past 20 years, showing that the observations from PASE are within the range of previous estimates but on the lower end. Because the entire aerosol size spectrum was measured during the flights we can go one step further by integrating the surface area spectrum to get the mass transfer rate and calculate the necessary $\mathrm{pH}$ to match the overall uptake rate. Faloona (2009) showed that at $\mathrm{H}_{2} \mathrm{O}_{2}$ concentrations of $\sim 1 \mathrm{ppbv}$ (typical of PASE observations: Heikes \& O'Sullivan, personal communication) $\mathrm{S}(\mathrm{IV})$ oxidation rates by $\mathrm{H}_{2} \mathrm{O}_{2}$ cannot exceed $\sim 10^{-3} \mathrm{~h}^{-1}$, independent of aerosol $\mathrm{pH}$. The estimate of $\mathrm{pH}$ then only depends on the ozone availability (13-19 ppbv during PASE) and the aerosol size spectrum, and both night flights indicate an aerosol $\mathrm{pH}$ of 6.9-7. As shown by Faloona (2009) the supermicron mode is responsible for the overwhelming majority of the heterogeneous S(IV) oxidation on marine aerosols so that

Table 2 Survey of past S(IV) oxidation rates in the MBL

\begin{tabular}{|c|c|c|}
\hline Sulfur Uptake/Oxidation $\left(\mathrm{h}^{-1}\right)$ & Notes & Source \\
\hline $0.12-0.20$ & $\mathrm{pH}=7$ & Sievering et al. (1991) \\
\hline 0.16 & uptake limit & Sievering et al. (1992) \\
\hline $0.08-0.68$ & model & Suhre et al. (1995) \\
\hline $0.05-0.35$ & model $(10 \mathrm{~m})$ & Mari et al. (1999) \\
\hline 0.04 & model & Chen et al. (2000) \\
\hline 0.06 & NSS-SO 4 budget & Huebert et al. (1996) \\
\hline 0.02 & $\mathrm{SO}_{2}$ budget & Bandy et al. (1996) \\
\hline $0.02-0.04$ & NSS-SO 4 budget & De Bruyn et al. (1998) \\
\hline 0.015 & SSA only & Luria and Sievering (1991) \\
\hline 0.03 & unconstrained & Mihalopoulos et al. (2007) \\
\hline 0.11 & Approx. Average & All Above \\
\hline
\end{tabular}


the $\mathrm{pH}$ estimates reported here are only applicable to that mode, as the overall loss rate is effectively independent of the exact $\mathrm{pH}$ of the submicron population.

Revisiting the daytime budgets now allows adjustment of the $\mathrm{SO}_{2}$ yield from DMS oxidation to permit reasonable values of aerosol loss. From a broad survey of literature estimates of $\gamma$ Faloona (2009) suggests $70 \%$ as a mean value. Using this yield, however, causes 3 of the 8 daytime budgets to have a positive residual (requiring a net $\mathrm{SO}_{2}$ source from heterogeneous chemistry in order to balance). A yield of unity, on the other hand, permits the closure of all the daytime budgets, within uncertainties, and provides a mean aerosol loss rate of $0.05 \mathrm{~h}^{-1}$, in line with that derived during the night flights, which were independent of $\gamma$. The multivariate regression model used to derive the first three terms in Table 1 also provides an estimate of the net error of the budget method (Conley et al. 2009). The average error estimate from all ten flights is $0.48 \mathrm{ppt} \mathrm{h}^{-1}$ or $0.01 \mathrm{~h}^{-1}$, which we consider to be a reasonable estimate of the $1 \sigma$ spread in the heterogeneous loss rate calculation using the scalar budget technique.

In an attempt to further our understanding of errors in the budget method, we used a statistical non-linear mixed effects model (NLMIXED in SAS) for the ten flights to estimate a value of $\gamma$, and derive an error estimate of the heterogeneous loss rates. Leaving $\gamma$ unconstrained, the $95 \%$ confidence interval was found to be $0.9-1.29$, but of course it is physically unrealistic that the reaction yield could exceed unity. This method does, however, give a sense of the uncertainty in our finding of near unity yield. Another way to view this is that with unity $\mathrm{SO}_{2}$ yield from DMS oxidation all eight daytime flights balance save for RF03 which exceeds balance (with no aerosol losses) by only $0.004 \mathrm{~h}^{-1}$, about half the $1 \sigma$ error estimate for that flight. Thus we consider $\gamma \approx 1$ to be most consistent with our observations. The results from PASE strongly suggest that the principal oxidant in the tropical MBL is OH (Conley et al. 2009) and according to Atkinson et al. (2004) the $\mathrm{OH}$ oxidation rate of DMS proceeds by three parts abstraction and 1 part addition at $297 \mathrm{~K}$, the average temperature observed in the MBL during this experiment. Turning to the estimate put forward by Chin et al. (1996),

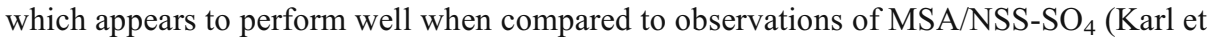
al. 2007), all of the abstraction channel and $75 \%$ of the addition channel yield $\mathrm{SO}_{2}$, leading to an overall yield of 0.94 at $297 \mathrm{~K}$. Using this value leads to RF14 showing no discernable aerosol loss, and RF03 exceeding balance by about two standard deviations, still somewhat compatible with our budget analysis.

The homogeneous oxidation of $\mathrm{SO}_{2}$ by $\mathrm{OH}$ is inferred from the loss rate of DMS (and confirmed by the $\mathrm{OH}$ measurements) using the three-body association reaction rate recommended by Atkinson et al. (2004) $\left(8.0 \times 10^{-13} \mathrm{~cm}^{3} \mathrm{molec}^{-1} \mathrm{~s}^{-1}\right.$ at $\left.298 \mathrm{~K}\right)$. A daytime average $\mathrm{OH}$ concentration of $5.1 \times 10^{6}$ molecules $\mathrm{cm}^{-3}$ (Conley et al. 2009) leads to a $0.015 \mathrm{~h}^{-1}$ daytime loss rate, or a 5.5 day lifetime of $\mathrm{SO}_{2}$ in the tropical MBL due to homogeneous oxidation. The inferred loss rate to $\mathrm{OH}$ is subtracted from the 'Net Loss' column of Table 1 before calculating the daytime aerosol loss rates. Figure 3 shows the $\mathrm{pH}$ dependence of the heterogeneous loss calculated from Eq. 5 for all ten flights. With a nominal 1.5 ppbv $\mathrm{H}_{2} \mathrm{O}_{2}$ (Heikes, personal communication), the different curves correspond to the differing aerosol surface areas and available ozone only. Of course, this technique is predicated on there being no other significant S(IV) oxidants in the aerosol, such as hypohalous acids (HOBr/HOCl) proposed by Vogt et al. (1996). The neglect of such acids is probably consistent with the finding of the minimal role played by $\mathrm{BrO}$ in the DMS budget of the region (Conley et al. 2009), but it cannot be ruled out altogether. In reality, the high heterogeneous oxidation rates observed could be explained by a lower $\mathrm{pH}$ and a great abundance of hypohalous acids scavenged by the supermicron aerosols. 
Fig. $3 \mathrm{SO}_{2}$ uptake and oxidation rates of all 10 flights calculated from the observed in-situ surface area spectrum and ozone concentration as a function of aerosol $\mathrm{pH}$

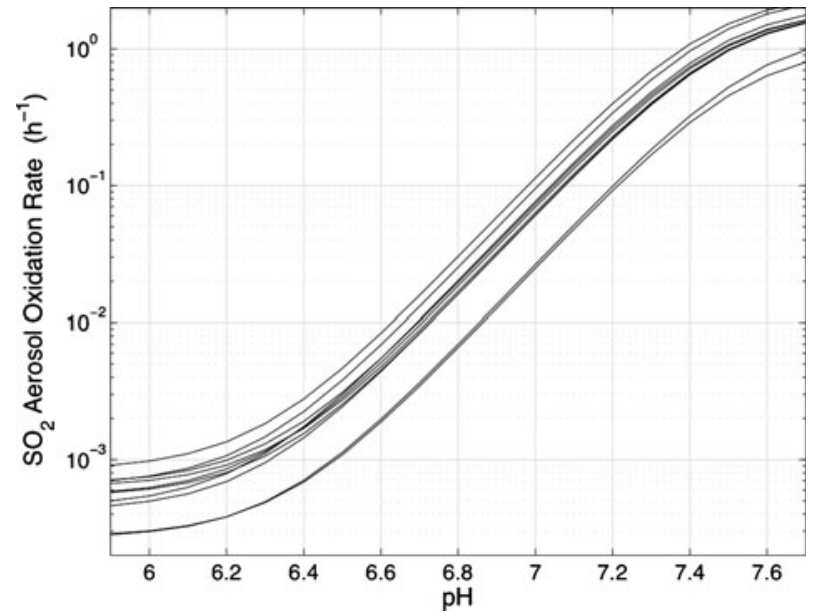

Several investigators have suggested that aerosol $\mathrm{pH}$ should, in theory, lower with increasing RH as occurs with height in most boundary layers (Chameides and Stelson 1992; Keene and Savoie 1998; von Glasow and Sander 2001). The modeling work of von Glasow and Sander (2001) indicate a fall of $2 \mathrm{pH}$ units in the span of $600 \mathrm{~m}$ across the MBL. Given the exponential behavior exhibited in Fig. 3, the heterogeneous oxidation of S(IV) would consequently drop quite precipitously with height and the bulk of the loss would be concentrated near the ocean surface. Such a strong gradient in loss rate would induce a positive curvature in the $\mathrm{SO}_{2}$ flux profile. This can be illustrated by taking the derivative with respect to height of Eq. 2 (Faloona et al. 2005) and neglecting the vertical derivatives of production, advection, and homogeneous loss:

$$
\frac{\partial^{2} C}{\partial t \partial z}=-\frac{\partial^{2}}{\partial z^{2}}\left\langle w^{\prime} c^{\prime}\right\rangle-\frac{\partial L_{\text {hetero }}}{\partial z} C-\frac{\partial C}{\partial z} L_{\text {hetero }} \approx 0
$$

Assuming that the mean vertical profile of $\mathrm{SO}_{2}$ reaches some quasi-stationary state, the three rhs terms are required to sum to zero. Scale analysis of the loss related terms shows that the one proportional to the vertical gradient of the heterogeneous loss rate dominates. Observed $\mathrm{SO}_{2}$ gradients during aircraft profiling never exceeded a few ppt in the lowest 50-100 m. Using the mean values form Table 1 and the slope of $L_{\text {hetero }}$ inferred from Fig. 3, the 2nd term above is $\sim\left(0.05 \mathrm{~h}^{-1} / 100 \mathrm{~m} \times 50 \mathrm{pptv}=2.5 \times 10^{-2} \mathrm{pptv} \mathrm{m}^{-1} \mathrm{~h}^{-1}\right)$ while the $3 \mathrm{rd}$


Because $L_{\text {hetero }}$ is positive definite in this formulation, a diminution of the loss rate with height (due to increasing $\mathrm{RH}$ and falling $\mathrm{pH}$ ) results in a positive curvature of the flux profile. More specifically this implies a smaller downward flux at the surface relative to the observations at $30 \mathrm{~m}$. Physically this may be interpreted as the observed flux aloft resulting from the sum of surface deposition and a net flux into the lowest layers below the measurement height where loss to aerosols would be greatest. Suhre et al. (1995) found exactly this type of flux curvature result in a one dimensional chemical model with the aerosol surface area fixed to a scale height of $200 \mathrm{~m}$ (their Figure 15). While no discernable aerosol gradients were ever observed in the surface layer during PASE, an analogous flux curvature would result from a lapse rate of $\mathrm{pH}$. Figure 4 shows the vertical flux divergence pattern observed over the course of RF01. The three colors represent measurements 


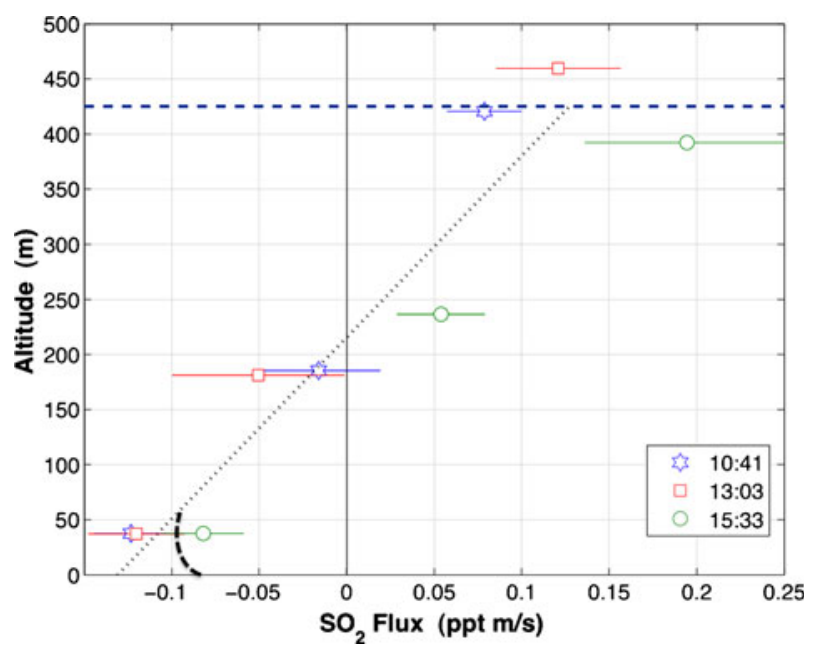

Fig. 4 The $\mathrm{SO}_{2}$ flux profile from research flight 1. The stars, squares, and circles represent the fluxes measured on different stacks of legs with the mean local time given in the legend. The horizontal dashed line represents the mean MBL height for the entire flight. The dotted line is a linear fit to the flux data giving the mean flux divergence (responsible for $-2.1 \mathrm{ppt} \mathrm{h}^{-1}$ loss on this flight), and the curved dashed portion represents the approximate flux curvature that would arise in the case of a pH falling from 7.1 to 6.8 in the lowest $100 \mathrm{~m}$

from the three consecutive flight stacks centered at the local times denoted in the legend, and the dotted line is a linear fit to all the data representing the observed flux divergence, $-2.1 \mathrm{ppt} \mathrm{h}^{-1}$ in this case. The dashed curve represents the impact of a hypothetical change in $\mathrm{pH}$ from 7.1 to 6.8 , and consequent drop in heterogeneous loss, over the lowest $100 \mathrm{~m}$. The curvature induced by the estimated 2nd term in Eq. 11 represents a change in flux divergence of $\sim 2.5 \mathrm{ppt} \mathrm{h}^{-1}$ in lowest $100 \mathrm{~m}$. Such an effect would make the dry deposition velocities derived during PASE even smaller bringing them farther out of agreement with theory (Section 3.3). While this does not rule out the possibility of a strong vertical $\mathrm{pH}$ gradient as purported by others, it certainly entreats further investigation of this phenomenon.

\section{2 $\mathrm{MBL} \mathrm{SO}_{2}$ throughputs}

The averages of all the budget terms are presented at the bottom of Table 1 separated into day and night flights, and the resultant diel average of both. Although the nigh-time MBL was undersampled during PASE, the diel average is considered more representative of the larger-scale budget because of the strong temporal asymmetry in $\mathrm{SO}_{2}$ processing (i.e., no production from DMS and no homogeneous oxidation at night.) The results of the diel mission averages are depicted in Fig. 5, showing the MBL column integrated fluxes of the $\mathrm{SO}_{2}$ processes in terms of $\mu \mathrm{mol} \mathrm{m} \mathrm{d}^{-1}$, and the corresponding $1 \sigma$ standard deviation of the means. The left panel of Fig. 5 illustrates the mean DMS (green, thick) and $\mathrm{SO}_{2}$ (red, thin) profiles from one daytime flight (solid lines), RF03, and one nighttime flight (dashed lines), RF06. Although the flights occurred a week apart, and the boundary layer depths are not exactly the same, the general behavior is clear. $\mathrm{SO}_{2}$ builds up throughout the day due to DMS oxidation, and decays at night due to aerosol uptake, dry deposition, and vertical mixing. Notice that both the turbulent exchange with the $\mathrm{BuL}$ and ocean uptake is 


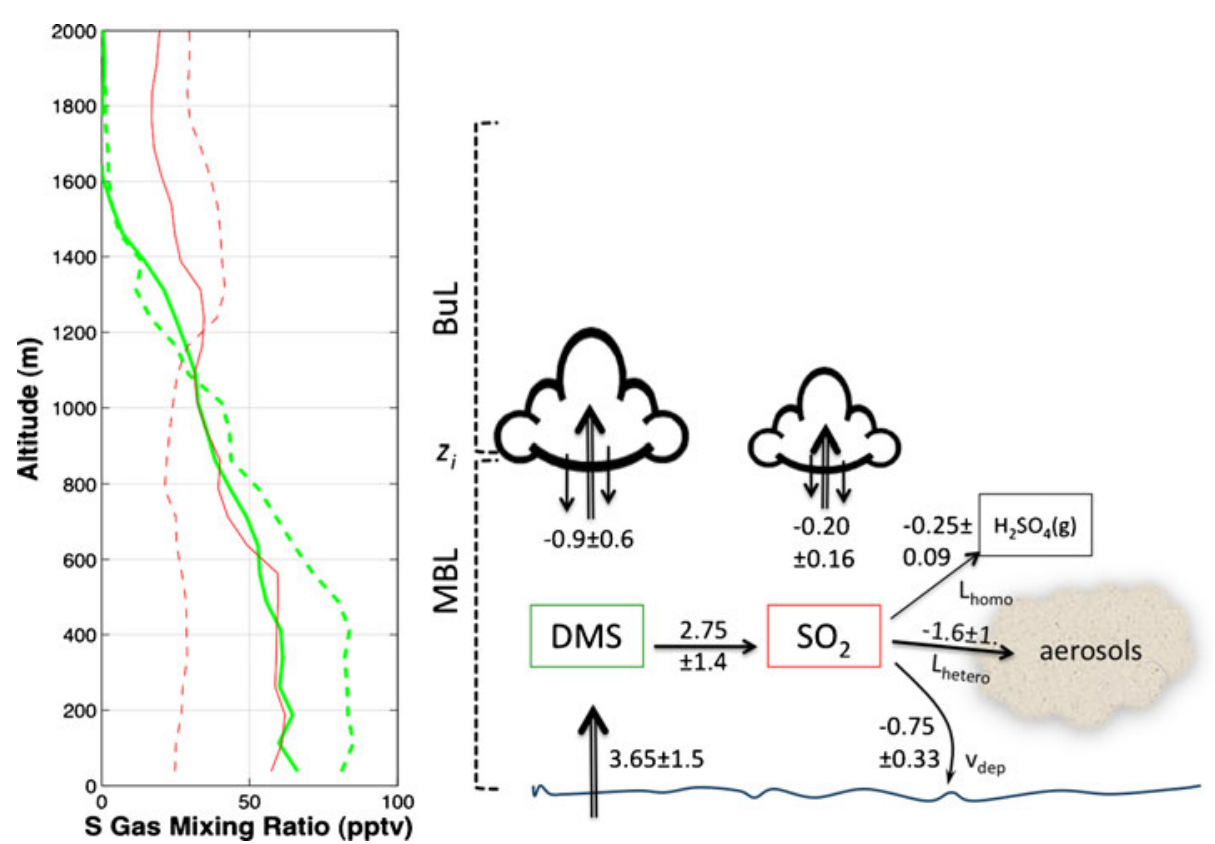

Fig. 5 (Left panel) vertical profiles of DMS (thick, green) and $\mathrm{SO}_{2}$ (thin, red) for typical daytime (solid) and nighttime (dashed) flights. (Right panel) graphic representation of the diel average sulfur fluxes, and the standard deviation of the means, observed during PASE. The units are $\mu \mathrm{mol} \mathrm{S} \mathrm{m} \mathrm{d}^{-1}$. The inversion heights, $z_{i}$, are not to scale and vary between flights

diminished overnight (due to reduced $\mathrm{MBL} \mathrm{SO}_{2}$ levels) leading to a reduction in the net turbulent flux divergence as evinced in Table 1. The overall diel picture is that of the $2.75 \mu \mathrm{mol} \mathrm{m} \mathrm{m}^{-2}$ produced from DMS oxidation, approximately $8 \%$ is lofted into the $\mathrm{BuL}$, another $10 \%$ reacts with $\mathrm{OH}$ in the $\mathrm{MBL}, 28 \%$ is deposited to the ocean surface, and $58 \%$ is oxidized on aerosols.

\subsection{Dry deposition}

Dry deposition removes many trace gases from the lower atmosphere. More specifically, with over $70 \%$ of the Earth's surface covered by seawater the uptake of trace species by the ocean provides a major mechanism for scrubbing soluble gases out of the atmosphere. Global chemical models of the atmospheric sulfur cycle indicate that surface dry deposition of $\mathrm{SO}_{2}$ results in a global lifetime of about 5 days and accounts for around one third of its total sink, but is one of the major sources of uncertainty in sulfur cycle modeling (Faloona 2009). The flux and mean $\mathrm{SO}_{2}$ observations from the lowest legs $(<50 \mathrm{~m}, n=61)$ of PASE result in an average $v_{d e p}$ just under $0.4 \mathrm{~cm} \mathrm{~s}^{-1}$ for $10 \mathrm{~m}$ winds ranging from 4.5 to $10 \mathrm{~ms}^{-1}$. Standard modeling approaches tend to assign somewhat larger $v_{d e p}$ over the ocean between 0.5 and $1.1 \mathrm{~cm} \mathrm{~s}^{-1}$ (Langner and Rodhe 1991; Pham et al. 1995; Yvon et al. 1996; Karl et al. 2007).

To investigate the reason for the difference, $v_{d e p}$ was estimated from the observed friction velocity and stability parameter $(z / L$, where $L$ is the Obukhov length) in Eqs. 8 through $10 . z / L$ ranged from -0.05 to -1.24 with a geometric mean of -0.33 , and the 
average Bowen ratio was found to be 0.05 . On average the aerodynamic resistance constituted about $80 \%$ of the total parameterized resistance. Additional $v_{d e p}$ calculations were made using the methods outlined in Fairall et al. (2000) and Fairall et al. (2007). Figure 6 illustrates a comparison of the observed and modeled $\mathrm{SO}_{2}$ deposition velocities from all the PASE surface layer legs (defined as $z<0.125 z_{i}$, mostly from 30 to $50 \mathrm{~m}$ above the ocean). While the data exhibit a correlation with the observed friction velocity, the observations are seen to fall $\sim 30 \%$ lower than the parameterizations of Wesely and Hicks (1977) and Fairall et al. (2007). On the other hand, use of Fairall et al. (2000, their equation 25) requires the specification of an uncertain coefficient which can be adjusted to improve the fit to the observations. The coefficient represents the length scale at which turbulent transport cannot compete with molecular diffusion near the interface. The authors suggest that this scale is approximately 10 times the Kolmogorov microscale (estimated as $\nu / u_{*}$, where $\nu$ is the molecular viscosity), but that there is scant empirical evidence justifying its exact magnitude. Adjusting this coefficient to 22 leads to matching the means of the Fairall et al. (2000) model and the observations to within 1\%, although significant scatter is still evident. Estimates of the uncertainty in the observed deposition velocities were made using the scatter of the flux observations along every leg combined with the relative standard deviation of the $\mathrm{SO}_{2}$ concentration, leading to an estimate of the mean error of $0.06 \mathrm{~cm} \mathrm{~s}^{-1}$.

The formulation of air-sea exchange using deposition velocity presupposes that there is no return flux of the gas from the ocean to the atmosphere, or more specifically, that the aqueous concentration is much less than its Henry's law equilibrium value. This is assumed to be true for $\mathrm{SO}_{2}$ given its rapid dissociation and subsequent oxidation of sulfite in sea water (Schwartz 1992; Nightingale and Liss 2003). Given a mean atmospheric concentration of $55 \mathrm{pptv}$, and an effective Henry's law constant of $2 \times 10^{7} \mathrm{M} \mathrm{atm}^{-1}$ at the $\mathrm{pH}$ of the ocean, dissolved S(IV) would need to be at levels of $\sim 330 \mu \mathrm{M}$ in order to diminish the expected $\mathrm{SO}_{2}$ deposition velocities by $30 \%$. The only sulfite measurement we could find reported concentrations less than $0.1 \mu \mathrm{M}$ (Campanella et al. 1995), but the sampling procedures and locations were not well documented. Nonetheless, elevated S(IV) in sea water seems to be an unlikely candidate to explain our results.

Fig. 6 Observed $\mathrm{SO}_{2}$ deposition velocities from all legs below $0.125 z_{i}$ compared with the aerodynamic component of resistance and several common parameterizations with respect to friction velocity. The Fairall et al. (2000) model has its leading coefficient, $\lambda_{1}$, set to 22 in order to best agree with the observations of this study

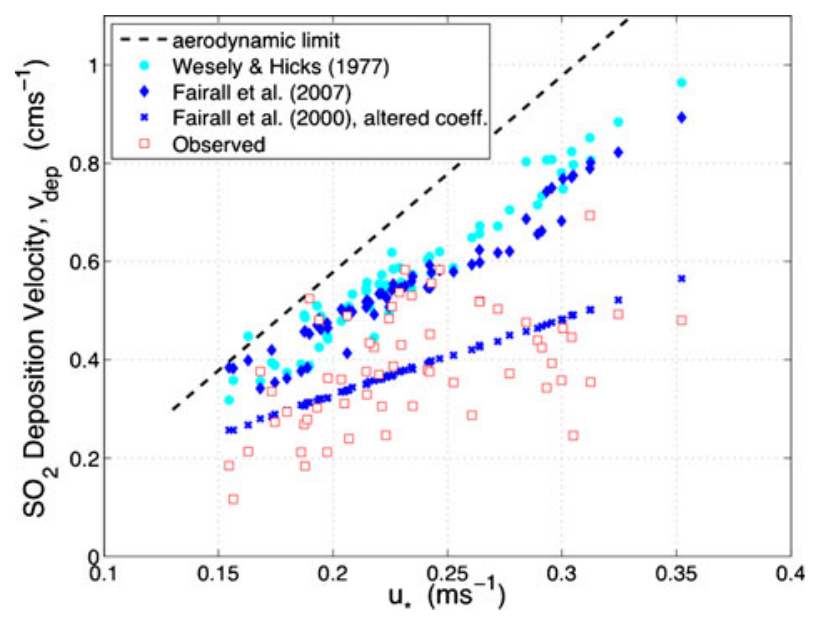




\section{Conclusions}

PASE comprised fourteen research flights on the NCAR C-130 over the equatorial Pacific from August 8 to September 9, 2007. The focused campaign marked a departure from typical airborne atmospheric chemistry experiments in its dedication to steady sampling in a slowly varying, relatively homogeneous environment. The use of multiple APIMS instruments to carefully monitor the vertical structure of the fluxes of DMS and $\mathrm{SO}_{2}$ by airborne eddy covariance allowed for a careful analysis of the entire mean scalar budget equation (what may be more readily recognizable to the chemistry community as a chemical mass balance.) Tracking the dynamical components of the sulfur gas's mixing enabled accurate estimation of the unconstrained chemistry by budget residuals. The mean estimate of the error of this budget method for $\mathrm{SO}_{2}, 0.01 \mathrm{~h}^{-1}$, indicates that any process acting on a timescale of up to 4 days can be resolved (at the $1 \sigma$ level) with this technique.

DMS and $\mathrm{SO}_{2}$ were found to be strongly related both spatially and temporally throughout the experiment. The mean gradients for both species were directed to the north-northeast and were correlated flight by flight. The daily cycles of the two species were out of phase as was observed at this site by Bandy et al. (1996), indicating that $\mathrm{SO}_{2}$ is derived primarily from DMS oxidation. However, a third of the flights indicated net transport of $\mathrm{SO}_{2}$ into the MBL from above, which could be indicative of long range transport of anthropogenic or volcanic sulfur from South America. The budget analysis of both $\mathrm{S}$ gases requires that DMS oxidation generates $\mathrm{SO}_{2}$ with near unity yield, and that $\mathrm{S}$ (IV) conversion on aerosols maintain rates between undetectable to $9.9 \% \mathrm{~h}^{-1}$, with a mean of about $5 \% \mathrm{~h}^{-1}$. Thus, the flight to flight variability of heterogeneous oxidation rates is significantly greater than the estimated mean error of the budget method $\left(1 \% \mathrm{~h}^{-1}\right)$. Given the known oxidation mechanisms from ozone and hydrogen peroxide in the aerosol phase, the inferred uptake rates imply that the $\mathrm{pH}$ of the supermicron aerosols is sustained near neutral. Furthermore, it appears that the large atmospheric variability of the uptake must be driven by small changes in aerosol $\mathrm{pH}$ (6.4-7.2), as the rates do not correlate with total aerosol surface area and ozone concentrations.

The eddy covariance measurements of $\mathrm{SO}_{2}$ fluxes to the ocean surface were found to vary with friction velocity as expected by theory, albeit with considerable data scatter, in part due to noise in the measurement derived from a fluctuating background. The observations of deposition velocity were found to be on average $30 \%$ lower than conventional theory. The budget averaged over both day and night flights indicate that less than $10 \%$ of the $\mathrm{SO}_{2}$ produced in-situ is mixed into the $\mathrm{BuL}$ above the $\mathrm{MBL}, 10 \%$ is converted to sulfuric acid in the gas phase, a bit over $25 \%$ is lost to dry deposition, and over half is removed on supermicron marine aerosols.

Acknowledgements This work was made possible by a grant from the atmospheric chemistry program of the National Science Foundation (grant \#ATM-0627227). The National Center for Atmospheric Research is sponsored by the National Science Foundation. The authors greatly appreciate the support and dedication exhibited by the pilots, managers, and support staff of NCAR's Research Aviation Facility. Further appreciation is due to Teresa Campos, Ilana Pollack, and Cliff Heizer for freely sharing their ozone data, as well as Brian Heikes, Dan O'Sullivan, and Amy Higbie for openess with their $\mathrm{H}_{2} \mathrm{O}_{2}$ data. Much of the effort of the first author was supported by the University of California's Agricultural Experiment Station. Assistance with the statistical modeling by Jerome Braun, Senior Statistician at UC Davis, is also greatly appreciated. Finally, the lead author is ever grateful to his wife, Justine Frischmann, for her boundless encouragement, keen mind, and patient heart. 
Open Access This article is distributed under the terms of the Creative Commons Attribution Noncommercial License which permits any noncommercial use, distribution, and reproduction in any medium, provided the original author(s) and source are credited.

\section{References}

Andreae, M.O., Raemdonck, H.: Dimethyl sulfide in the surface ocean and the marine atmosphere-a global view. Science 221(4612), 744-747 (1983)

Atkinson, B.W., Zhang, J.W.: Mesoscale shallow convection in the atmosphere. Rev. Geophys. 34(4), 403431 (1996)

Atkinson, R., Baulch, D.L., Cox, R.A., Crowley, J.N., Hampson, R.F., Hynes, R.G., et al.: Evaluated kinetic and photochemical data for atmospheric chemistry: Volume $\mathrm{i}-$ gas phase reactions of o-x, hox, nox and sox species. Atmos. Chem. Phys. 4, 1461-1738 (2004)

Bandy, A.R., Scott, D.L., Blomquist, B.W., Chen, S.M., Thornton, D.C.: Low yields of so2 from dimethyl sulfide oxidation in the marine boundary-layer. Geophys. Res. Lett. 19(11), 1125-1127 (1992)

Bandy, A., Thornton, D.C., Blomquist, B.W., Chen, S., Wade, T.P., Ianni, J.C., et al.: Chemistry of dimethyl sulfide in the equatorial pacific atmosphere. Geophys. Res. Lett. 23(7), 741-744 (1996)

Bandy, A.R., Thornton, D.C., Tu, F.H., Blomquist, B.W., Nadler, W., Mitchell, G.M., et al.: Determination of the vertical flux of dimethyl sulfide by eddy correlation and atmospheric pressure ionization mass spectrometry (APIMS). J. Geophys. Res. Atmos. 107(D24), 4743 (2002). doi:10.1029/2002JD002472

Barnes, I., Hjorth, J., Mihalopoulos, N.: Dimethyl sulfide and dimethyl sulfoxide and their oxidation in the atmosphere. Chem. Rev. 106(3), 940-975 (2006)

Benoit, R.: Integral of surface-layer profile-gradient functions. J. Appl. Meteorol. 16(8), 859-860 (1977)

Blomquist, B.W., Huebert, B.J., Fairall, C.W.: Determining the sea-air flux of dimethylsulfide by eddy correlation using mass spectrometry. Atmospheric Measurement Techniques Discussions 2, 1973-2025 (2009)

Campanella, L., Cipriani, P., Martini, T.M., Sammartino, M.P., Tomassetti, M.: New enzyme sensor for sulfite analysis in sea and river water samples. Anal. Chim. Acta 305(1-3), 32-41 (1995)

Chameides, W.L., Stelson, A.W.: Aqueous-phase chemical processes in deliquescent sea-salt aerosols - a mechanism that couples the atmospheric cycles of s and sea salt. J. Geophys. Res. Atmos. 97(D18), 20565-20580 (1992)

Charlson, R.J., Lovelock, J.E., Andreae, M.O., Warren, S.G.: Oceanic phytoplankton, atmospheric sulphur, cloud albedo and climate. Nature 326, 655-661 (1987)

Chen, G., Davis, D.D., Kasibhatla, P., Bandy, A.R., Thornton, D.C., Huebert, B.J., et al.: A study of dms oxidation in the tropics: Comparison of christmas island field observations of dms, so2, and dmso with model simulations. J. Atmos. Chem. 37(2), 137-160 (2000)

Chin, M.A., Jacob, D.J., Gardner, G.M., ForemanFowler, M.S., Spiro, P.A., Savoie, D.L.: A global threedimensional model of tropospheric sulfate. J. Geophys. Res. Atmos. 101(D13), 18667-18690 (1996)

Clarke, A.D., Shinozuka, Y., Kapustin, V.N., Howell, S., Huebert, B., Doherty, S., et al.: Size distributions and mixtures of dust and black carbon aerosol in asian outflow: Physiochemistry and optical properties. J. Geophys. Res. Atmos. 109(D15), D15S09 (2004). doi:10.1029/2003JD004378

Clarke, A.D., Owens, S.R. Zhou, J.C.: An ultrafine sea-salt flux from breaking waves: Implications for cloud condensation nuclei in the remote marine atmosphere. J. Geophys. Res. Atmos. 111(D6), D06202 (2006). doi:10.1029/2005JD006565

Conley, S., Faloona, I., Miller, G.H., Blomquist, B., Lenschow, D., Bandy, A.: Closing the dimethyl sulfide budget in the tropical marine boundary layer during the pacific atmospheric sulfur experiment. Atmos. Chem. Phys. Discuss. 9, 17265-17296 (2009)

Davis, D., Chen, G., Bandy, A., Thornton, D., Eisele, F., Mauldin, L., et al.: Dimethyl sulfide oxidation in the equatorial pacific: Comparison of model simulations with field observations for dms, so2, h2so4(g), msa (g), ms, and nss. J. Geophys. Res. Atmos. 104(D5), 5765-5784 (1999)

De Bruyn, W.J., Bates, T.S., Cainey, J.M., Saltzman, E.S.: Shipboard measurements of dimethyl sulfide and so2 southwest of tasmania during the first aerosol characterization experiment (ace 1). J. Geophys. Res. Atmos. 103(D13), 16703-16711 (1998)

De Bruyn, W.J., Harvey, M., Cainey, J.M., Saltzman, E.S.: Dms and so2 at baring head, new zealand: Implications for the yield of so2 from dms. J. Atmos. Chem. 41(2), 189-209 (2002)

DeLacy, B.G., Bandy, A.R.: The determination of carbon dioxide concentration using atmospheric pressure ionization mass spectrometry/isotopic dilution and errors in concentration measurements caused by dryers. J. Environ. Qual. 37(4), 1354-1359 (2008) 
Eisele, F.L., Berresheim, H.: High-pressure chemical ionization flow reactor for real-time massspectrometric detection of sulfur gases and unsaturated-hydrocarbons in air. Anal. Chem. 64(3), 283-288 (1992)

Fairall, C.W., Hare, J.E., Edson, J.B., McGillis, W.: Parameterization and micrometeorological measurement of air-sea gas transfer. Bound.-Lay. Meteorol. 96(1-2), 63-105 (2000)

Fairall, C.W., Helmig, D., Ganzeveld, L., Hare, J.: Water-side turbulence enhancement of ozone deposition to the ocean. Atmos. Chem. Phys. 7, 443-451 (2007)

Faloona, I.: Sulfur processing in the marine atmospheric boundary layer: A review and critical assessment of modeling uncertainties. Atmos. Environ. 43(18), 2841-2854 (2009)

Faloona, I., Lenschow, D.H., Campos, T., Stevens, B., van Zanten, M., Blomquist, B., et al.: Observations of entrainment in eastern pacific marine stratocumulus using three conserved scalars. J. Atmos. Sci. 62(9), 3268-3285 (2005)

Fuchs, N.A., Sutugin, A.G.: Highly Dispersed Aerosol. Elsevier, New York (1970)

Hicks, B.B., McMillen, R.T.: On the measurement of dry deposition using imperfect sensors and in non-ideal terrain. Bound.-Lay. Meteorol. 42(1-2), 79-94 (1988)

Howell, S.G., Clarke, A.D., Shinozuka, Y., Kapustin, V., McNaughton, C.S., Huebert, B.J., et al.: Influence of relative humidity upon pollution and dust during ace-asia: Size distributions and implications for optical properties. J. Geophys. Res. Atmos. 111(D6), D06205 (2006). doi:10.1029/2004JD005759

Huebert, B.J., Howell, S., Laj, P., Johnson, J.E., Bates, T.S., Quinn, P.K., et al.: Observations of the atmospheric sulfur cycle on saga-3. J. Geophys. Res. Atmos. 98(D9), 16985-16995 (1993)

Huebert, B.J., Zhuang, L.Z., Howell, S., Noone, K., Noone, B.: Sulfate, nitrate, methanesulfonate, chloride, ammonium, and sodium measurements from ship, island, and aircraft during the atlantic stratocumulus transition experiment marine aerosol gas exchange. J. Geophys. Res. Atmos. 101(D2), 4413-4423 (1996)

Kapustin, V.N., Clarke, A.D., Shinozuka, Y., Howell, S., Brekhovskikh, V., Nakajima, T., et al.: On the determination of a cloud condensation nuclei from satellite: Challenges and possibilities. J. Geophys. Res. Atmos. 111(D4), D04202 (2006). doi:10.1029/2004JD005527

Karl, M., Gross, A., Leck, C. Pirjola, L.: Intercomparison of dimethylsulfide oxidation mechanisms for the marine boundary layer: Gaseous and particulate sulfur constituents. J. Geophys. Res. Atmos. 112(D15), D15304 (2007). doi:10.1029/2006JD007914

Keene, W.C., Savoie, D.L.: The ph of deliquesced sea-salt aerosol in polluted marine air. Geophys. Res. Lett. 25(12), 2181-2184 (1998)

Koch, D., Jacob, D., Tegen, I., Rind, D., Chin, M.: Tropospheric sulfur simulation and sulfate direct radiative forcing in the goddard institute for space studies general circulation model. J. Geophys. Res. Atmos. 104 (D19), 23799-23822 (1999)

Langner, J., Rodhe, H.: A global 3-dimensional model of the tropospheric sulfur cycle. J. Atmos. Chem. 13 (3), 225-263 (1991)

Leck, C., Bigg, E.K.: Source and evolution of the marine aerosol-a new perspective. Geophys. Res. Lett. 32 (19), L19803 (2005). doi:10.1029/2005GL023651

Lovelock, J.E., Maggs, R.J., Rasmusse, R.: Atmospheric dimethyl sulfide and natural sulfur cycle. Nature 237(5356), 452-453 (1972)

Luria, M., Sievering, H.: Heterogeneous and homogeneous oxidation of so2 in the remote marine atmosphere. Atmos. Environ., A Gen. Topics 25(8), 1489-1496 (1991)

Mari, C., Suhre, K., Rosset, R., Bates, T.S., Huebert, B.J., Bandy, A.R., et al.: One-dimensional modeling of sulfur species during the first aerosol characterization experiment (ace 1) lagrangian b. J. Geophys. Res. Atmos. 104(D17), 21733-21749 (1999)

Maroulis, P.J., Bandy, A.R.: Estimate of contribution of biologically produced dimethyl sulfide to global sulfur cycle. Science 196(4290), 647-648 (1977)

Massman, W.J.: A review of the molecular diffusivities of h2o, co2, ch4, co, o-3, so2, nh3, n2o, no, and no2 in air, o-2 and n-2 near stp. Atmos. Environ. 32(6), 1111-1127 (1998)

Matt, D.R., McMillen, R.T., Womack, J.D., Hicks, B.B.: A comparison of estimated and measured so2 deposition velocities. Water Air Soil Pollut. 36(3-4), 331-347 (1987)

Meyers, T.P., Finkelstein, P., Clarke, J., Ellestad, T.G., Sims, P.F.: A multilayer model for inferring dry deposition using standard meteorological measurements. J. Geophys. Res. Atmos. 103(D17), 2264522661 (1998)

Mihalopoulos, N., Kerminen, V.M., Kanakidou, M., Berresheim, H., Sciare, J.: Formation of particulate sulfur species (sulfate and methanesulfonate) during summer over the eastern mediterranean: A modelling approach. Atmos. Environ. 41(32), 6860-6871 (2007)

Möhler, O., Arnold, F.: Gaseous sulfuric-acid and sulfur-dioxide measurements in the arctic troposphere and lower stratosphere-implications for hydroxyl radical abundances. Geophys. Res. Lett. 19(17), 17631766 (1992) 
Nightingale, P.D., Liss, P.S.: Gases in seawater. In: Holland, H.D., Turekian, K.K. (eds.) Treatise on Geochemistry, Vol 6: The Oceans and Marine Geochemistry. Elsevier-Pergamon, Oxford (2003)

O’Dowd, C.D., Lowe, J.A., Smith, M.H., Kaye, A.D.: The relative importance of non-sea-salt sulphate and sea-salt aerosol to the marine cloud condensation nuclei population: An improved multi-component aerosol-cloud droplet parametrization. Q. J. Roy. Meteorol. Soc. 125(556), 1295-1313 (1999)

Padro, J., Neumann, H.H., Denhartog, G.: Dry deposition velocity estimates of so2 from models and measurements over a deciduous forest in winter. Water Air Soil Pollut. 68(3-4), 325-339 (1993)

Patroescu, I.V., Barnes, I., Becker, K.H., Mihalopoulos, N.: Ft-ir product study of the oh-initiated oxidation of dms in the presence of nox. Atmos. Environ. 33(1), 25-35 (1999)

Pham, M., Muller, J.F., Brasseur, G.P., Granier, C., Megie, G.: A three-dimensional study of the tropospheric sulfur cycle. J. Geophys. Res. Atmos. 100(D12), 26061-26092 (1995)

Putaud, J.P., Mihalopoulos, N., Nguyen, B.C., Campin, J.M., Belviso, S.: Seasonal-variations of atmospheric sulfur-dioxide and dimethylsulfide concentrations at amsterdam island in the southern indian-ocean. J. Atmos. Chem 15(2), 117-131 (1992)

Sander, R.: Modeling atmospheric chemistry: Interactions between gas-phase species and liquid cloud/ aerosol particles. Surv. Geophys. 20(1), 1-31 (1999)

Schwartz, S.E.: Mass-transport consideration pertinent to aqueous-phase reactions of gases in liquid-water clouds. In: Jaechske, W. (ed.) Chemistry of Multiphase Atmospheric Systems. Springer, Heidelberg (1986)

Schwartz, S.E.: Factors governing dry deposition of gases to surface water. In: Schwartz, S.E., Slinn, W.G.N. (eds.) Precipitation Scavenging and Atmosphere-Surface Exchange: Volume ii. Hemisphere Publishing Corp, Washington (1992)

Shon, Z.H., Davis, D., Chen, G., Grodzinsky, G., Bandy, A., Thornton, D., et al.: Evaluation of the dms flux and its conversion to so2 over the southern ocean. Atmos. Environ. 35(1), 159-172 (2001)

Sievering, H., Boatman, J., Galloway, J., Keene, W., Kim, Y., Luria, M., et al.: Heterogeneous sulfur conversion in sea-salt aerosol-particles - the role of aerosol water-content and size distribution. Atmos. Environ., A Gen. Topics 25(8), 1479-1487 (1991)

Sievering, H., Boatman, J., Gorman, E., Kim, Y., Anderson, L., Ennis, G., et al.: Removal of sulfur from the marine boundary-layer by ozone oxidation in sea-salt aerosols. Nature 360(6404), 571-573 (1992)

Song, C.H., Chen, G., Davis, D.D.: Chemical evolution and dispersion of ship plumes in the remote marine boundary layer: Investigation of sulfur chemistry. Atmos. Environ. 37(19), 2663-2679 (2003)

Stevens, B., Lenschow, D.H., Vali, G., Gerber, H., Bandy, A., Blomquist, B., et al.: Dynamics and chemistry of marine stratocumulus-dycoms-ii. Bull. Am. Meteorol. Soc. 84(5), 579-593 (2003)

Suhre, K., Andreae, M.O., Rosset, R.: Biogenic sulfur emissions and aerosols over the tropical south-atlantic .2. One-dimensional simulation of sulfur chemistry in the marine boundary-layer. J. Geophys. Res. Atmos. 100(D6), 11323-11334 (1995)

Tang, I.N., Tridico, A.C., Fung, K.H.: Thermodynamic and optical properties of sea salt aerosols. J. Geophys. Res. Atmos. 102(D19), 23269-23275 (1997)

Thornton, D.C., Bandy, A.R., Tu, F.H., Blomquist, B.W., Mitchell, G.M., Nadler, W., et al.: Fast airborne sulfur dioxide measurements by atmospheric pressure ionization mass spectrometry (apims). J. Geophys. Res. Atmos. 107(D22), 12 (2002)

Vogt, R., Crutzen, P.J., Sander, R.: A mechanism for halogen release from sea-salt aerosol in the remote marine boundary layer. Nature 383(6598), 327-330 (1996)

von Glasow, R., Sander, R.: Variation of sea salt aerosol ph with relative humidity. Geophys. Res. Lett. 28(2), 247-250 (2001)

Webb, E.K., Pearman, G.I., Leuning, R.: Correction of flux measurements for density effects due to heat and water-vapor transfer. Q. J. Roy. Meteorol. Soc. 106(447), 85-100 (1980)

Wesely, M.L., Hicks, B.B.: Some factors that affect deposition rates of sulfur-dioxide and similar gases on vegetation. J. Air Pollut. Control Assoc. 27(11), 1110-1116 (1977)

Wesely, M.L., Hicks, B.B.: A review of the current status of knowledge on dry deposition. Atmos. Environ. 34(12-14), 2261-2282 (2000)

Yvon, S.A., Saltzman, E.S., Cooper, D.J., Bates, T.S., Thompson, A.M.: Atmospheric sulfur cycling in the tropical pacific marine boundary layer (12 degrees s,135 degrees w): A comparison of field data and model results .1. Dimethylsulfide. J. Geophys. Res. Atmos. 101(D3), 6899-6909 (1996) 